\title{
REGULAR EL MERCADO O SALUD COMO DERECHO
}

\author{
Regulate the MARKet, OR HEALth AS A RIGHT
}

En momentos en que se debate una nueva reforma al sistema de aseguramiento en salud, debemos plantearnos una pregunta: ¿Es suficiente regular el mercado de seguros privados? ¿O los niveles de desigualdad y segregación en nuestro sistema sanitario, requieren una transformación que implique tener una salud consagrada como derecho?

\section{Antecedentes}

La salud en Chile se comporta como un bien de consumo. Esto lo podemos verificar mediante la observación de la forma en la cual se financia el sistema. Las estadísticas que entrega Chile a la OCDE son claras: un 38,2\% del gasto sanitario proviene del gasto directo de las familias en salud, los seguros privados corresponden a un 16,8\%, lo que contrasta con el 44,8\% que se aporta por cotizaciones (FONASA) y el aporte fiscal. Cuando esto se compara con las respectivas poblaciones a cargo del sector público y privado, se puede apreciar una creciente desigualdad en la distribución del gasto sanitario. Un beneficiario de los seguros privados de salud, tiene un gasto promedio dos veces mayor que el beneficiario del FONASA. Por otro lado, la constatación de la distribución del gasto sanitario nos da a entender que hemos construido el acceso a la salud según el criterio de la capacidad de pago. Este tipo de elementos nos muestra que estamos en presencia de un "bien de mercado" y no frente a un derecho.

Los problemas no se reducen a este elemento; además de producirse una división del "mercado" sanitario por capacidad de pago, debemos sumar una variable relacionada con la segmentación por riesgo. Este tipo de partición es perversa y aparece por el efecto que tienen las Isapre en el conjunto del sistema. Esta clase de empresas, al tener como objetivo la maximización de las utilidades de sus accionistas, buscan seleccionar a sus beneficiarios, tratando de minimizar el riesgo a enfermar en sus respectivas carteras de clientes.

\section{Entre fallos y comisiones}

En este marco de desigualdad y segregación, es que en agosto del 2010 el Tribunal Constitucional emite un fallo que declara inconstitucional la tabla de factores de riesgo, por considerar que, dado que las Isapre reciben fondos de la seguridad social (7\% de cotización legal), no deben discriminar y deben atenerse a la lógica de la seguridad social, ya que utilizan sus recursos. Esto abre una serie de implicaciones que exigen una reforma al actual sistema de "seguros". Desde el 2010 a la fecha han existido ya varias comisiones. La llamada “comisión Illanes” generó dos propuestas; una de 
mayoría, que incluía un fondo de compensación de riesgo y la disolución de las Isapre, las cuales podrían derivar en entidades de seguridad social. La propuesta de minoría planteaba que era necesario generar subsidios desde el Estado a las Isapre para compensar el "riesgo" asociado a una afiliación abierta. Estas propuestas son desechadas por la administración de Piñera e ingresa al Congreso una ley corta y un IPC de salud. Al poco andar esta "ley corta” es retirada por el Ejecutivo a raíz de la falta de apoyo político, por lo que el gobierno de Piñera retira la ley y convoca a una nueva comisión, esta vez con una precaución: la comisión debe atenerse a crear un "plan garantizado de salud" (PGS) para las Isapre, dejando de lado la posibilidad de generar cambios al esquema de financiamiento de la salud en Chile. Como era de esperar, la comisión entrega un informe ad hoc a su objetivo, con lo cual el ejecutivo envía el proyecto de ley del PGS. No obstante, este proyecto de ley queda empantanado en el Congreso.

Con el triunfo de Michelle Bachelet se retira el proyecto del plan garantizado de salud y se conforma una nueva comisión. Sin embargo, las declaraciones del nuevo gobierno también apuntan a realizar una reforma circunscrita a las Isapre y no al sistema en general. Por otro lado, la confirmación de esta nueva comisión asesora presidencial excluye a actores sociales como los usuarios y gremios. A pesar de aquello, existen dos representantes de las Isapre y uno de las clínicas.

\section{Regular el mercado o derecho a la salud}

Los aspectos que esta nueva comisión pretende abordar están relacionados con el problema de la discriminación en la tarificación de los planes de salud, los reajustes a los valores de los planes, y respecto a los copagos. Al igual que la anterior comisión, esta debe entregar una propuesta para el sistema privado. De esta forma estamos frente a una posible propuesta que implica morigerar los elementos más abusivos del sistema y regular la competencia del mercado.

En el limitado esquema de la discusión que hoy se presenta en la comisión, pensamos que es posible avanzar en generar una lógica de seguridad social. Esto implicaría la formulación de propuestas de carácter funcional, como por ejemplo que exista una afiliación abierta en los seguros privados, la generación de un plan de salud único, similar al que hoy entrega la modalidad institucional del FONASA, y que incluya el seguro de incapacidad laboral (SIL), financiado con el $7 \%$ de cotización (aumentando el tope en las cotizaciones). Asimismo, es de suma importancia generar mejores coberturas financieras en los planes para reducir los copagos. Otro elemento que debe ser incorporado en una "reforma" es el término de la integración vertical, mecanismo mediante el cual los grandes holdings de salud son capaces de orientar la demanda de salud a prestadores miembros del mismo holding, provocando que "el dinero quede en familia".

No obstante lo anterior, a juicio de Fundación Creando Salud, avanzar en una "regulación del mercado" o terminar con ciertos abusos de la industria no implica que se esté dando paso a un esquema en el cual la salud sea concebida como un derecho social garantizado. Si bien los "abusos" de las Isapre requieren ser eliminados por completo, avanzar en una lógica regulatoria es preservar el mercado al interior del aseguramiento de la salud y no su extinción. Por otra parte, una regulación del mercado de seguros no alcanzaría a resolver los problemas anteriormente expuestos. Una salida al problema de la desigualdad y segregación requiere desmercantilizar. En el área del aseguramiento, la propuesta que levantamos desde la Fundación implica la construcción de un seguro público único que administre el total de los recursos de la seguridad social y los seguros privados deben remitirse a ser "seguros complementarios". Otra posible salida, es avanzar a un financiamiento de la salud basado en impuestos generales, pero esto tendría que convivir con una estructura tributaria diferente a la que hoy tenemos, dado que financiar la salud de esta forma, podría implicar caer en la regresividad, ya que la actual estructura impositiva no es progresiva. 